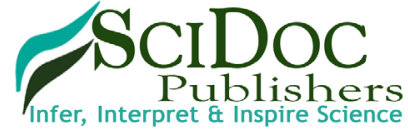

International Journal of Diabetology \& Vascular Disease Research (IJDVR) ISSN:2328-353X

\title{
Diabetic Foot Lesions on Rise, Investigating Predicting Factors in a Developing Country
}

Research Article

Maali Gumaa MM*, Mohamed Shwaib H, Suad M. Ali

Faculty of Medicine, Department of Community Medicine, University of Khartoum, Khartoum Sudan, Sudan.

\section{Abstract}

Background: Diabetic foot lesions (DFL) are one of the devastating complications of diabetes mellitus (DM). Numerous factors interlinked to cause DFL which starts as ulcer \& end up as amputation. Apart from the direct effect on individuals it has indirect impact on society in terms of decreased productivity. Large scale preventive programs targeting predicting factors of DFL are needed to minimize its burden.

The aim of this study is to investigate multiple predicting factors of DFL on poor, limited resources community to aid in fighting this disease.

Materials \& Methods: This is an analytical case control study conducted in Jabir Abu Alaiz diabetic centre in Khartoum Sudan in june \& july 2014. 88 adult DFL patients were enrolled as cases \& 182 adult diabetic patients were enrolled as controls. Data were collected on DM duration, glycaemic control, neuropathy, vasculopathy, retinopathy, feet deformity, history of ulcers among demographic \& other variables. Frequency matching was done on design stage. Bivariate \& multivariate analysis were conducted for multiple possible predicting factors.

Results: Recurrent ulcers (OR 3.525 95\% CI (1.66-7.48) p-value (0.001)), \& feet deformity (OR 3.186 95\% CI (1.6-6.3) $\mathrm{p}$-value $(0.001))$ proved to be statistically significant predicting variables. Suboptimal foot care clinics visits \& diabetic foot wear was observed.

Conclusion: Recurrent ulcers \& feet deformity are predicting factors to DFL among others. Those diabetic patients should be aware about suitable preventive methods against DFL. Health education about foot care clinics role \& enhancement of their utilization beside diabetic foot wear is mandatory.

Keywords: Diabetic Foot Lesions; Recurrent Ulcers; Feet Deformity; Foot Care Clinics; Diabetic Foot Wear.

\section{Introduction}

Diabetes Mellitus (DM) is a rising pandemic outbreak. Its estimated prevalence was 285 million $(6 \cdot 4 \%)$ in 2010 , and its predicted to rise to around 439 million $(7 \cdot 7 \%)$ by 2030 [1]. The rise in prevalence is predicted to be much greater in developing than in developed countries $(69 \%$ vs $20 \%)$ [2].

In Africa, the prevalence of DM in 2010 was 12.1 million $(3 \bullet 8 \%)$ [1].

Diabetic foot lesions (DFL) are estimated to affect 15\% to $25 \%$ of people with diabetes at some time in their lives [3].
A study in Palestine stated that every 20 seconds a lower limb is lost somewhere of the world due to diabetes [4].

DFL is a common disabling problem and frequently leads to amputation of the leg. They precede $25 \%$ to $90 \%$ of all amputations [5]. This very disabling long-term complication of diabetes mellitus (DFL) is also called diabetic foot syndrome [6].

A clinical important manifestation of the diabetic foot syndrome is the diabetic foot ulcer, sometimes followed by amputation [6].

In 2005 the International Diabetes Federation (IDF) published a position statement about common diabetes complications [7]. In this statement, data from epidemiological studies have indicated

\section{*Corresponding Author:}

Mohamed Maali Gumaa Mohamed,

Faculty of Medicine, Department of Community Medicine, Orthopedic Surgery \& Traumatology Board SMSB, University of Khartoum, P.O. Box 102, Khartoum Sudan, Sudan. Tel: 00249918107123

E-mail: mmjuofk@hotmail.com

Received: January 09, 2016

Accepted: February 22, 2016

Published: February 23, 2016

Citation: Maali Gumaa MM, Mohamed Shwaib H, Suad M. Ali (2016) Diabetic Foot Lesions on Rise, Investigating Predicting Factors in a Developing Country. Int J Diabetol Vasc Dis Res,. 4(2), 154-161. doi: http://dx.doi.org/10.19070/2328-353X-1600033

Copyright: Maali Gumaa $\mathbf{M}^{\circ}$ 2016. This is an open-access article distributed under the terms of the Creative Commons Attribution License, which permits unrestricted use, distribution and reproduction in any medium, provided the original author and source are credited. 
that between $40-70 \%$ of all lower extremity amputations are related to diabetes. $85 \%$ of all amputations related to diabetes are preceded by foot ulcers.

As one of the most common complications of diabetes in the lower extremity is the diabetic foot ulcer, an estimated $15 \%$ of patients with diabetes will develop a lower extremity ulcer during the course of their disease. Several population-based studies indicate a $0.5 \%$ to $3 \%$ annual cumulative incidence of diabetic foot ulcers.

According to one large British study of neuropathic patients, the 1 -year incidence of initial foot ulcer was 7\% [8]. The prevalence of foot ulcers reported for a variety of populations ranges from $2 \%$ to $10 \%[8]$.

While 7 to $20 \%$ of patients with foot ulcers will subsequently require an amputation, foot ulceration is the precursor to approximately $85 \%$ of lower extremity of amputations in persons with diabetes [8].

Diabetes continues to be the most common underlying cause of non-traumatic lower extremity amputations (LEAs) in the US and Europe. More than $60 \%$ of LEAs in the US occur in people with diabetes, averaging 82,000 per year [8].

Twenty percent of all diabetic persons enter the hospital because of foot problems. One study in UK showed that $50 \%$ of the hospital bed occupancy of diabetic patients is caused by foot problems [9].

Approximately $85 \%$ of non-traumatic major amputations among people with diabetes are preceded by a diabetic foot ulcer (DFU). These DFUs defined as any necrosis, gangrene, or full-thickness skin defect occurring distal to the ankle in a diabetic patient serve as the portal of entry for severe foot infections, and the endstage complication may be limb loss through major (above-ankle) amputation [10].

Moreover, DFL incur huge socioeconomic burden on societies. In 2007, the treatment of diabetes and its complications in the United States cost around 116 billion American dollars on its direct expenses, and at least $33 \%$ of these costs were linked to the treatment of foot ulcers $[7,11]$. Notably, the higher the ulcer grade the higher the cost of care.

Other studies showed that the socio-economic burden incurred due to diabetes and related complications such as amputations are immense [12].

These include direct costs of medication, hospitalization, cost of treatment, and supplies [12].

In the Arab region (including Sudan) the prevalence of D.M. has been rising dramatically within the last two decades. This may be attributed to the changes that occurred in the Arab world cultures towards westernization [7].

The cost of care of diabetes and its complications in Arab countries, in comparison with the United States and Europe, unfortunately has a small budget directed to it [7].
DFUs are analogous to many cancers in that the diagnosis and management of certain identifiable/visible precursor states may halt progression of disease and reduce end-stage complications [10].

Researchers established that between $49-85 \%$ of all amputations can be prevented [7].

A study showed that amputation rate can be reduced by more than $50 \%$ if certain strategies had being followed [5].

This means that significant reductions in amputation rates can be achieved by adopting well structured preventive policies.

Concerning Sudan, DM is a common medical problem and diabetic septic foot infection is a serious complication; with considerable morbidity and mortality.

According to studies, In Khartoum, Sudan, DFL is the most common cause of Major lower limb amputation [4].

In low resources developing country like Sudan, simple, inexpensive, easily administered public health interventions are possible to be implemented if evidence from research guide the decision-makers \& legislators for action.

The aim of this study is to investigate the prevailing main predicting factors of DFL in low resource situation (Khartoum Sudan) to aid in targeting those factors by suitable interventions to minimize the burden of this disease.

\section{Materials and Methods}

\section{Design}

Observational, hospital-based retrospective case control study.

\section{Setting}

This study was conducted in Jabir Abu Alaiz diabetic center in Khartoum Sudan in surgery clinic \& internal medicine clinic.

\section{Participants}

Previously diagnosed adult diabetic patients ( $>18$ years) in Khartoum state in 2014.

\section{Diabetic patient: (according to WHO definition)}

Patient diagnosed as Type 1 or 2 D.M. by fasting/ 2 hour postprandial glucose tolerance test (GTT) on LAB (venous sample). Satisfying the cutoff point of $126-\mathrm{mg} / \mathrm{dl}$ fasting \& 200 $\mathrm{mg} / \mathrm{dl} 2 \mathrm{~h}$ postprandial.

Impaired glucose tolerant test subjects IGT (pre-diabetic stage) i.e. those have fasting glucose level between $110-125 \mathrm{mg} / \mathrm{dl}$ or $2 \mathrm{~h}$ pp between 140-200 mg/dl are excluded from the study.

Diagnosis by venous sample only (not dipstick capillary sample/ not urine). 
Diagnosis of diabetes by HBA1c $(>6.5 \%)$ is not used in this study. Diabetic foot lesion patient: (applied for cases only)

Diabetic patient (according to the above stated criteria) with full thickness wound or ulcer on either foot surfaces (planter or dorsal) distal to both malleolus of any surface area \&/or depth not healed for more than 1 week.

Lesions should be of Wagners* class 1 or more (not 0 ).

This definition necessarily excludes hand lesions.

\section{Inclusion criteria:}

- Newly diagnosed DFL patient (wound within 2 week from presentation).

- Any patient with recurrent wound (healed old wound) more than 1 year is regarded as new DFL.

\section{Exclusion criteria:}

- Patients less than 18 years of age.

- Newly or incidentally diagnosed patient with diabetes (at least to be known diabetic for 3 years). (Controls criterion).

- Patients unfit to participate in the study e.g. confused, febrile.

- Patients with known foot lesions due to causes other than D.M.

\section{Sampling}

Sample size: According to the formula $\mathrm{N}=(\mathrm{Z})^{2 * 4 p}(1-\mathrm{p}) /(\mathrm{d})^{2}$

Where:-

$\mathrm{n}=$ number of study participant

$\mathrm{Z}=$ critical ratio (at $95 \%$ C.I. its 1.96 )

$\mathrm{P}=$ prevalence of outcome variable (in this study of DFL)

$\mathrm{D}=$ desired margin of error (customary $5 \%$ )

The sample sized will be divided for cases \& controls by matching ratio of (2) in order that every case will be matched with 2 controls ( $\mathrm{R}$ to $1 \mathrm{R}=2$ ).

As prevalence of DFL is not known precisely here in Sudan. By substitution in the above formula (using data from study done in Nairobi Kenya which gave prevalence of DFL $=4.5 \%(0.045)$ ) [13] the estimated sample size will be about 264 .

To account for unexpected issues sample size will be taken as $\mathbf{2 7 0}$ subjects in total. 90 cases \& 180 controls, by the ratio of case: control of 1:2.

Sample type $\boldsymbol{\&}$ selection: As no consistent frame found, the initially presented patients represent convenient sample, but from those presented.

Probability systematic interval random sample: The first participant was determined randomly from a list usually taken of the daily newly presenting patients in both surgery/medicine clinics, then another participant after every fixed interval of participants was chosen. (every other one in surgery clinic, every two in medicine clinic).

The average time of data collection was 45 days ( $>6$ weeks).
The total number collected was 88 cases, 182 controls. Data collection method

A structured pre-designed, pre-tested, pre-coded, close ended interview administered questionnaire was used for data collection.

Pilot testing of the questionnaire was done on random sample of JADC, Cronbach alpha scale of questionnaire was (0.65).

4 trained doctors performed data collection. (2 in surgery clinic \& 2 in medicine clinic).

Data was gathered from direct patient interviews, past records \& registries in the centre.

10 gram monofilament, with $128 \mathrm{~Hz}$ tuning fork devices was used by the same data collector in the clinics to check \& grade neuropathy.

Hand held Dopller device was used in the U/S department to measure ABPI \& grade vasculopathy of presented subjects.

All of the devices mentioned above are the same $\&$ was used to all participants in consistent manner to maintain \& maximize internal validity

\section{Ethical consent}

- Voluntary informed consent was obtained from all participant after explaining \& clarifying all concerns verbally.

- approval was sought \& obtained from the designated ethical clearance committee.

- permission was sought from the JADC director.

\section{Variables}

Demographic Variables: Age, sex, residency, education, income. Education \& income variables were combined together to give an estimate of the socio-economic status.

\section{Study variables:}

\section{Independent variables:}

Glycaemic control according to the past 3 months results (modified from standardized questionnaire \& scale) [14], smoking habit (current/past), current or past suffering or diagnosis of vision impairment \&/or cataract/retinopathy.

History of trauma or injury to the foot, (current/past).

Presence or absence of deformity in the feet, those specified for this study were:- (any one detected indicate deformity).

(Flat foot/Hallux valgus/Hallux rigidus/Ingrowing, fissured nails/Callosities/Claw toes/Dry cracked skin).

Features of neuropathy (parasthesia/numbness/fall of shoes out while walking).

Loss of protective sensation in this study is defined as lack of sensation with 10 -gm monofilament test on foot planter surface 
\&/or vibration sensation with $128-\mathrm{HZ}$ tuning fork on malleolus.

Features of vascular insufficiency in term of past diagnosis of vascular insufficiency disease \& (ABPI grade) (0.9-1.1= normal, $<0.9$ or $>1.1=$ abnormal).

Perfusion assessment include pedal assessment (dorsalis pedis/ posterior tibial arteries).

Peripheral arterial disease is regarded present if ABPI is less 0.9 \&/or absent both pedal pulses.

\section{Dependent variables:}

The development of DFL (i.e. presence or absence of wound).

\section{Data management $\&$ analysis}

Data sorting, editing \& cleaning was performed by the prime investigator, field data check was done by the prime investigator, SPSS version 22 was used for analysis, results are presented in form of tables, graphs, \& percentages.

Point estimate were determined (odd ratios), interval estimate were also be calculated (confidence intervals), \& test of significance were done (P-values).

\section{Confounding variables}

Matching was performed between cases \& controls in the following possible confounding variables:-

Age/smoking history/history of previous foot care clinic visit/ diabetic foot shoes wear.

Matching was done in the design stage.

It was frequency matching, not individual matching.

Binary logistic regression \& modeling was done for the analysis. Significance was reported from $<0.05,95$ CI were mentioned.

\section{Results}

The total studied sample size was 270 participant, 88 DFL patients (cases) \& 182 diabetic patients (controls).
Univariate analysis showed that elderly age groups were the predominant in both cases \& controls, however, cases were predominantly males, of low S.E. status, unlike controls.

More than $1 / 3^{\text {rd }}$ of cases were from rural areas, in contrast to less than $1 / 5^{\text {th }}$ of controls (Table 1$)$.

Frequency matching in the design stage was done on the following variables.

Bivariate analysis of possible predicting factors for DFL showed that all of the tested factors are significantly different between cases \& controls on 5\% significant level i.e. p-value $<0.05$ (Table 3).

Multiple possible predicting variables for DFL were tested in multivariate binary logistic regression model.

Factors proved significant statistical contribution to this model on $5 \%$ significance level $(\mathrm{p}$ value $<0.05$ ) were:-

History of recurrent ulcers, feet deformity (both p-value $=0.001$ ). (Table 4).

In both of cases \& controls, most participants (72.5\%) had no previous visit to diabetic foot care clinics (Figure 1).

Figure (1) shows percentages of previous foot care clinic visit in both cases \& controls $(\mathrm{No}=72.5 /$ yes $=27.5)$.

More than $2 / 3^{\text {rd }}$ of cases $\&$ controls $(64.7 \%)$, did not use diabetic foot wear Figure (2).

\section{Discussion}

Diabetic foot lesions are one of the major complications of DM that needs more focus on \& address in order to minimize its burden on individual \& society.

This study sampled 88 DFL patients \& 182 DM patients without foot lesions to highlight the common predicting factors on limited resources community.

Table 1: Shows frequency distribution of base-line characteristics among cases $\&$ controls.

\begin{tabular}{|c|c|c|c|}
\hline & Cases & Controls & P value* \\
\hline Frequency/percentage & $88(32.6 \%)$ & $182(67.4 \%)$ & 0.086 \\
\hline $\begin{array}{c}\text { Age }(\%) \\
(>55 / 36-55 / 18-35)\end{array}$ & $55.7 / 40.9 / 3.4$ & $41.8 / 45.6 / 12.6$ & 0.003 \\
\hline $\begin{array}{c}\text { Sex (\%) } \\
(\mathrm{M}=\text { male / F=female) }\end{array}$ & $\mathrm{M}=67 \%, \mathrm{~F}=33 \%$ & $\mathrm{M}=47.8 \%, \mathrm{~F}=52.2$ & 0.006 \\
\hline $\begin{array}{c}\text { S.E. status (\%)** } \\
(\text { low } / \text { average } / \text { high })\end{array}$ & $64.8 \%, 31.8 \%, 3.4 \%$ & $44 \%, 50 \%, 6 \%$ & $<0.0001$ \\
\hline $\begin{array}{c}\text { Residence (\%) } \\
(\mathrm{U}=\text { urban } / \mathrm{R}=\text { rural })\end{array}$ & $\mathrm{U}=62.5 \%, \mathrm{R}=37.5 \%$ & $\mathrm{U}=83 \%, 17 \%$ & \\
\hline
\end{tabular}

$*_{\text {test }}$ of significant difference between cases \& controls by chi-square test.

$* *$ S.E. status $=$ socio-economic status. 
Table 2. Shows distribution of matched on variables on cases vs. controls.

\begin{tabular}{|c|c|c|c|}
\hline Variable & $\begin{array}{c}\text { Frequency among } \\
\text { cases (\%) }\end{array}$ & $\begin{array}{c}\text { Frequency among } \\
\text { controls (\%) }\end{array}$ & P value* \\
\hline $\begin{array}{c}\text { Age } \\
(>55,36-55, \text { 18-35) years }\end{array}$ & $55.7 / 40.9 / 3.4$ & $41.8 / 45.6 / 12.6$ & 0.086 \\
\hline $\begin{array}{c}\text { Smoking status } \\
\text { (Yes, no) }\end{array}$ & $23.9 / 76.1$ & $26.4 / 73.6$ & 0.748 \\
\hline $\begin{array}{c}\text { Previous foot care clinic visit } \\
\text { (Yes, no) }\end{array}$ & $22.7 / 77.3$ & $29.7 / 70.3$ & 0.332 \\
\hline $\begin{array}{c}\text { Diabetic foot shoes wear } \\
\text { (Yes, no) }\end{array}$ & $33.0 / 67.0$ & $36.3 / 63.7$ & 0.947 \\
\hline
\end{tabular}

$*_{\text {test }}$ of significant difference between cases \& controls by chi-square test.

Table 3. Shows test of significance difference between cases $\&$ controls.

\begin{tabular}{|c|c|}
\hline Variable & P value* \\
\hline Recurrent ulcers & $<0.0001$ \\
\hline Feet deformity & $<0.0001$ \\
\hline Glycaemic control & $<0.0001$ \\
\hline Neuropathy & 0.001 \\
\hline Vasculopathy & 0.007 \\
\hline Retinopathy & 0.032 \\
\hline
\end{tabular}

*test of significant difference between cases \& controls by chi-square test.

Table 4. Shows output of logistic regression model.

\begin{tabular}{|c|c|c|c|}
\hline Variables & OR* & $\mathbf{9 5 \%}$ CI of OR** & P value \\
\hline Recurrent ulcers & 3.525 & $1.66-7.48$ & 0.001 \\
\hline Feet deformity & 3.19 & $1.6-6.3$ & 0.001 \\
\hline Sex & 0.59 & $0.30-1.16$ & 0.131 \\
\hline Residence & 0.55 & $0.27-1.09$ & 0.087 \\
\hline S.E. status & 1.43 & $0.24-8.06$ & 0.684 \\
\hline Vasculopathy & 1.4 & $0.5-3.8$ & 0.502 \\
\hline Neuropathy & 1.43 & $0.64-3.18$ & 0.381 \\
\hline Retinopathy & 0.79 & $0.40-1.58$ & 0.512 \\
\hline Glycaemic control & 0.73 & $0.44-1.19$ & 0.208 \\
\hline
\end{tabular}

$* \mathrm{OR}=$ odd ratio

${ }^{* *} \mathrm{CI}=$ confidence interval

Univariate analysis of the sample showed the predominace of elderly aged participants in both cases \& controls, which coincides with fact that DM (mainly Type 2) is a chronic disease with long term complications [15].

Regarding gender, most cases were males unlike controls, \& this difference was statistically significant, Studies in literature show that males usually found to be more than females as cases of DFL. This finding was similar to others [16-19] although it failed to attain significant contribution in this study multivariate analysis model, however, it suggests a relationship between gender \& DFL development. This relationship could be explained by the fact that males are more prone to outdoor activities \& occupational movement in comparison to females. This might be the cause of recurrent trauma \& injury to the feet. But on the other hand, other studies reported reverse male to female ratio $[12,20]$.

Regarding S.E. status, most cases were of low S.E. status, unlike controls whom mostly were of average S.E. status, also this different was statistically significant.

This finding may also suggest an association between S.E. status \& DFL development, although it failed to show significant contribution in study model of DFL development, this could be 
Figure 1. Shows percentages of previous foot care clinic visit in both cases $\&$ controls.

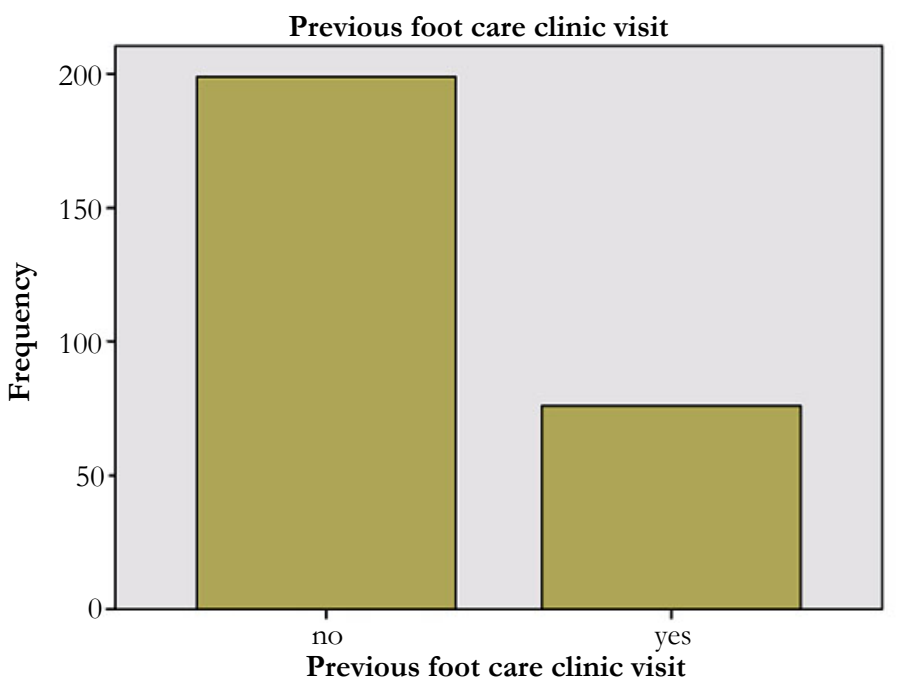

Figure 2. Shows percentages of practice of diabetic foot wear in both cases $\&$ controls.

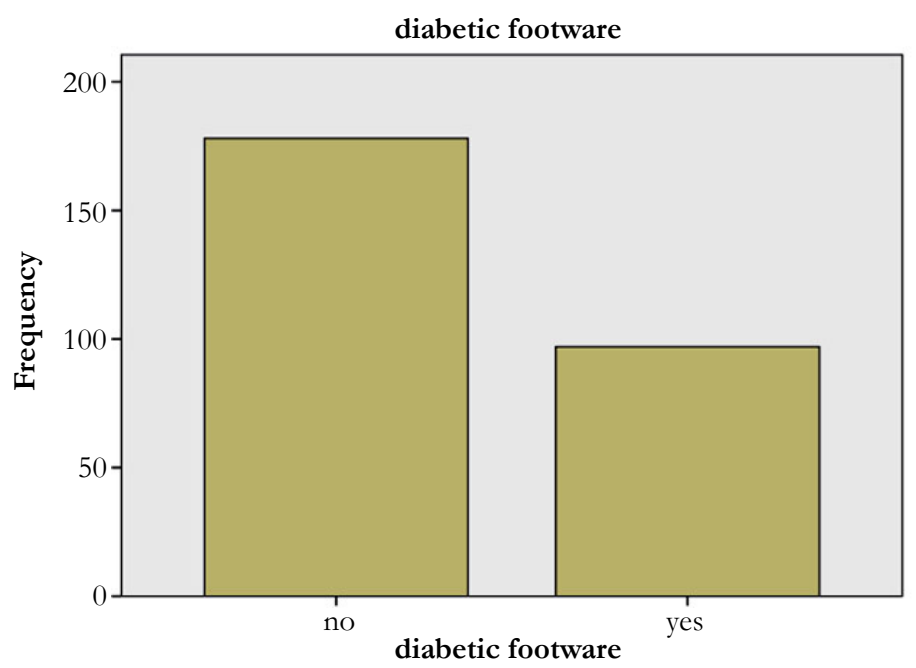

explained by the fact that poor people are usually less educated about DM \& its complications \& so have less awareness of how to prevent DFL. Moreover financial issues might play a major role in decreasing poor people sought of medical advice early on or compliance with prescribed treatment.

As found \& shown in most participant in this study $(62.5-83 \%)$ are from urban belongings (mostly khartoum state \& nearby towns), this was almost the same finding from other study which report up to $72 \%$ urban residency [19].

When considering cases in comparison to controls, $(37.5 \%)$ of cases were from rural areas, in contrast to $(17 \%)$ from controls, $\&$ this difference found to be significant, suggesting association between residence \& development of DFL. This finding resembles the finding in Ethiopian study [19].

This finding could be explained as rural residents are usually manual workers, farmers, herdsmen with more exposure to trauma \& injury in the field than urban residents with mostly office type of work.

Matching was tried in this study in the design stage in variables thought by the investigator that are associated by the outcome \& could confound the final results.
So why we tried to make both comparative groups of case \& controls sharing the same distribution of matched variables in a frequency matching pattern.

Those variables were (age/smoking history/previous visit to foot care clinic/diabetic foot shoes wear).

Identical matching was difficult to achieve due to limitation of time \& resources, but acceptable matching level was attained. All 4 matched on variables had no statistical significant difference between cases \& controls (Table 2).

In addition to demograghic factors apart from age, other 6 possible predicting factors were found to be significantly different between cases \& controls in bivariate analysis Table (3).

As expected matched on variables will not share or contribute in the model of logistic regression used \& so by definition are not studied risk factors or predictors in this study. Then, we examined multiple risk factors as predictors for the outcome of foot wound among diabetic patients, using binary logistic model, among many factors ( 9 factors) the study showed that:-

1-recurrent ulcers $(\mathrm{p}$ value $=0.001)$, O.R. $=3.5,95 \% \mathrm{CI}(1.67-4.84)$ 
2-feet deformity ( $\mathrm{p}$ value $=0.001)$, O.R. $=3.295 \%$ CI (1.6-6.33).

The strongest predictor reported by the model in this study was history of recurrent ulcers ( $\mathrm{p}$ value $=0.001$, with odd ratio of 3.5 , 95\% CI (1.7-7.5), indicating that according to the studied sample, if the participant had history of ulcer before, he/she is 3.5 times more probably prone to develop wound than those with no history of ulcers.

This finding is predictable, as diabetics whom have previous history of DFL usually have the same aggregation of risk factors persistent with them, $\&$ if diabetics do not change their behavior or modify their practice they will recurrently develop DFL.

Moreover, as multiple factors synergize together to end up with DFL, diabetics with previous history of DFL harbor the collection of all those risk factors which might be deficient in other diabetics without DFL.

Any feature indicates feet deformity (as prescribed in methodology section) puts diabetics at $>3$ times probability to develop DFL than others with no deformity.

This finding is related to the fact that biomechanics \& weight bearing areas in the foot play important role in development of DFL. Long term effects of hyper glycaemia usually result in polyneuropathies which affect small muscles of the foot \& result in altered load distribution \& increased friction in certain sites (e.g head of metatarsals).

Moreover, autonomic neuropathies lead to decreased sweating \& dry cracked skin, fissured nails all increased probability of ulcer development \& delayed healing process. So why deformity proved significantly contributing to DFL development \& so why prevention \& early detection of deformity is mandatory to reduce DFL development.

On the other hand, other studied factors in this study (Sex, residence, S.E. status, glycaemic control, retinopathy, neuropathy, vasculopathy) failed to attain significant statistical contribution.

Those factors showed to be significant predictors in other studies $[4,16,18,21-23]$.

In spite that glycaemic control, retinopathy, neuropathy, vasculopathy factors showed no significant statistical contribution to the model above, those factors showed statistical difference between cases \& control groups, with chi square values (Table 3).

Failure to achieve significance could be due to differences in study design, studied sample characteristics, relatively small sample size \& low study power, or due to chosen sample was inadequately representative to the source population. This could justify specifically for residence variable, which approached but didn't reach significance level ( $\mathrm{p}$ value 0.087 ).

Regarding retinopathy, failure to detect significant prediction to DFL might stem from the fact that all diabetics (were cases or controls) share the pathology similarly, with other factors contributing to causation.

Lack of objective method for detecting retinopathy \& relying on patient response might distort the results \& explain the deviation from normal conclusion as in other studies. Validation is required in future studies.

Glycaemic control was assessed using a modified scale adopted from international scale (DSMC) [14] to replace the lack of $\mathrm{HBa} 1 \mathrm{c}$ level record in a lot of studied participants. This modified scale were not used before on large scale \& so why might not reflect the real level intended to be measured.

That may explain why glycaemic control failed to attain significant contribution to the model, if it was at all.

Although validation was tried in assessment of vasculopathy by using ABPI, lack of objective results in majority of participants due to a lot of out of control reasons for measuring vasculopathy $\&$ relying on patients recall memory might also explain lack of significance in this model unlike other studies.

Most participant (especially cases) were newly presenting to JADC, were given appointment for ABPI for a lot of weeks later beyond the study time frame, so why large proportion of participant had no record for ABPI \& data collectors relied on memory of previous investigations.

Regarding neuropathy, there were difficulties reported by data collectors in detecting features of neuropathy either by history or examination.

Validation was performed by $10 \mathrm{gm}$ monofilament testing, \& $128 \mathrm{~Hz}$ tuning forks, but both history \&/or examination were encountered by difficulties in communication. This could be the cause why neuropathy unlike other previous studies failed to attain significant contribution to the model.

Although previous foot care clinic visit variable was matched between the two groups (so why cases/controls will not be discussed separately here), its a partial restriction as subjects might report visiting or not.

$72 \%$ of overall participant report no previous visiting to foot care clinic in contrast to $27 \%$ of others who report previous visit (Figure 1).

This represent suboptimal level of practice which may reflect the decreased level of knowledge of diabetics. Foot care clinics are generally newly introduced in Sudan $\&$ are not well developed yet so why they need more emphasis on usage.

(Figure 2) show that (63.7-67\%) of study participant report not wearing diabetic foot shoes (matched variable). This finding also reflects the decreased knowledge about the important protective roles of such shoes. Some respondents stated that they are not convinced by any benefits from these shoes, others replied that those shoes might even harm them more than protecting them, others report only financial restrictions from using those shoes.

Overall, predicting factors investigated \& discussed in this study coincides with most relevant literature.

Threats to validity that may affect this study include information bias in the form of recall bias as all case control studies. Reliance 
on the memory of participant regarding numerous past exposures might result in inaccurate results. The investigator tried as much as possible to verify any information if records exist.

Also, selection bias might represent one of the threats to validity in this study, as included samples might not perfectly represent the source population.

Matching in this study was not perfect due to limitations of time $\&$ resources, individually matched larger size case control studies are recommended in the future with larger funds.

Other known or unknown confounding variables might distort the relationship between the studied independent variables \& the dependent outcome variable. The investigator tried to control as much as possible some confounding variables, but other factors should be tried to control in any succeeding studies, with larger fund \& team.

One of limitations of this study is being facility-based. DM \& its DFL complication became wide spread in the community \& so further future research is recommended to be community-based.

\section{Conclusion}

This study found that males, low S.E. status \& rural residents are probably more prone to develop DFL. Many predicting variables were studied in this comparative study. Among many, those prove statistical significance for predicting DFL were:- (History of recurrent ulcer, deformity of feet).

The study also found that the majority of diabetic participant did not visit foot care clinic previously \& mostly they did not hear about it at all. Most of diabetics also don't wear diabetic foot shoes.

In general, we recommend diabetics to be motivated to educate themselves about DFL, its causes \& risk factors, how to fight \& prevent it. Diabetics specifically with feet deformities and/or history of previous ulcers need to regularly consider \& practice foot care at home $\&$ /or visit foot care clinics.

We recommend health care providers to examine regularly feet of diabetic patients looking for deformities, \& checking their foot care practice, \& to encourage diabetic patients with history of DFL to regularly visit foot care clinics \& practice home foot care practice.

We recommend health policy makers to initiate \& promote education campaigns targeting healthy people \& diabetics to raise awareness about DM \& its complications mainly DFL \& its predictors, \& to invest more effort $\&$ resources in diabetic foot care clinics.

\section{Acknowledgement}

Great thanks to professor Elrashied Ahmed Abdullah the director of JADC for his valuable contribution.

Thanks to all JADC staff who made valuable contribution to this work \& special thanks to Dr. Ahmed Edress, Dr. Mahir, Dr. Ensaf Badry \& Dr. Omer Ebrahim.

Thanks to department of community medicine university of Khartoum for their invaluable advice, supervision \& editing of this work.

\section{References}

[1]. Shaw JE, Sicree RA, Zimmet PZ (2010) Global estimates of the prevalence of diabetes for 2010 and 2030. Diabetes Res Clin Pract 87(1): 4-14.

[2]. Gonzalez EL, Johansson S, Wallander MA, Rodriguez LA (2009) Trends in the prevalence and incidence of diabetes in the UK: 1996-2005. J Epidemiol Community Health 63(4): 332-336.

[3]. Singh N, Armstrong DG, Lipsky BA (2005) Preventing foot ulcers in patients with diabetes. JAMA 293(2): 217-228.

[4]. Hassan Ata Abu Obaid, Ashraf Eljedi (2015) Risk Factors for the Development of Diabetic Foot Ulcers in Gaza Strip: A Case-Control Study. Int J Diabet Res 4(1): 1-6.

[5]. Global Lower Extremity Amputation Study Group (2000) Epidemiology of lower extremity amputation in centres in Europe, North America and East Asia. The Global Lower Extremity Amputation Study Group. Br J Surg 87(3): 328-337.

[6]. Shahin ES, Qalawa SAA, Mohamed MA, El-Ata ABA (2013) Quality of life satisfaction of diabetic foot patients: Comparative study. J Am Sci 9(1): 474-483.

[7]. Ahmed AA, Elsharief E, Alsharief A (2011) The Diabetic Foot in the Arab World. J Diabet Foot Complications 3(3): 55-61.

[8]. Frykberg RG, Zgonis T, Armstrong DG, Driver VR, Giurini JM, et al. (2006) Diabetic foot disorders. A clinical practice guideline (2006 revision). J Foot Ankle Surg 45(5 Suppl): S1-66.

[9]. Rodrigues J, Mitta N (2011) Diabetic Foot and Gangrene. Gangrene - Current Concepts and Management Options. InTech Publisher. 121-145.

[10]. Barshes NR, Sigireddi M, Wrobel JS, Mahankali A, Robbins JM, et al. (2013) The system of care for the diabetic foot: objectives, outcomes, and opportunities. Diabet Foot Ankle 4: 10.3402/dfa.v4i0.21847.

[11]. Boulton AJ, Vileikyte L, Ragnarson-Tennvall G, Apelqvist J (2005) The global burden of diabetic foot disease. Lancet 366 (9498): 1719-1724.

[12]. Kibachio JM, Omolo J, Muriuki Z, Juma R, Karugu L, et al. (2013) Risk factors for diabetic foot ulcers in type 2 diabetes: a case control study, Nyeri, Kenya. African J Diabet Med 21(1): 1-20.

[13]. Nyamu PN, Otieno CF, Amayo EO, Mcligeyo SO (2003) Risk factors and prevalence of diabetic foot ulcers at Kenyatta National Hospital, Nairobi. East Afr Med J 80(1): 36-43.

[14]. Schmitt A, Gahr A, Hermanns N, Kulzer B, Huber J, et al. (2013) The Diabetes Self-Management Questionnaire DSMQ): development and evaluation of an instrument to assess diabetes self-care activities associated with glycaemic control. Health Qual Life Outcomes 11: 138.

[15]. Longmore M, Wilkinson IB, Baldwin A, Wallin E (2014) Oxford Handbook of Clinical Medicine. ( $9^{\text {th }}$ edtn), Oxford University Press, UK. 198.

[16]. Ahmed S, Ahmed HA, Alhassan SF (2013) Factors Associated with Diabetic Septic Foot Among Patients Attending the Diabetic Septic Foot Unit in the Military Hospital, Khartoum State, Sudan. Sudan J Med Sci 1(2): 98-102.

[17]. El Bushra AD (2007) Diabetic Septic Foot Lesions in El Obeid, Western Sudan. Sudan J Med Sci 2(2): 119-122.

[18]. Ahmad W, Khan IA, Ghaffar S, Al-Swailmi FK, Khan I (2013) Risk factors for diabetic foot ulcer. J Ayub Med Coll Abbottabad 25(1-2): 16-18.

[19]. Deribe B, Woldemichael K, Nemera G (2014) Prevalence and Factors Influencing Diabetic Foot Ulcer among Diabetic Patients Attending Arbaminch Hospital, South Ethiopia. J Diabetes Metab 5: 322.

[20]. Al-Laham RY, Ali EM, Ahmed ME (2008) The risk factors for development of a diabetic foot in asymptomatic diabetics. Sudan Med J 44(1): 19-23.

[21]. Lawrence CN, Ionescu-Tirgoviste C (2008) Risk factors and clinical characteritics for foot ulcers in patients with diabetes in Bucharest, Romania. Proc Rom Acad Series B 1-2: 49-52.

[22]. Boyko EJ, Ahroni JH, Stensel V, Forsberg RC, Davignon DR, et al. (1999) A Prospective Study of Risk Factors for Diabetic Foot Ulcer. The Seattle Diabetic Foot Study. Diabetes care 22(7): 1036-1042.

[23]. Ogbera OA, Osa E, Edo A, Chukwum E (2008) Common Clinical Features of Diabetic Foot Ulcers: Perspectives From a Developing Nation. Int J Low Extrem Wounds 7(2): 93-98. 